\title{
Biomarkers in the triage of chest pain: are we making progress?
}

\author{
"Importantly, this field is still plagued by limited data and controlled \\ approaches are clearly needed to overcome bias of cohort or register \\ studies. Therefore, randomized clinical trials are paramount and now \\ on their way to be initiated."
} First draft submitted: 4 February 2016; Accepted for publication: 8 February 2016;
Published online: 22 March 2016

Keywords: acute myocardial infarction $\bullet$ chest pain $\bullet$ diagnosis $\bullet$ rule-out $\bullet$ troponin

\section{Triaging acute coronary syndrome: the clinical setting}

Patients with acute onset chest pain frequently present at the emergency department (ED). These patients can make up to $10 \%$ of all patients in the ED utilizing scarce medical resources [1]. Importantly, only around 20\% have a final diagnosis of acute myocardial infarction (AMI). Therefore, a rapid rule-out of AMI is urgently needed to limit the overuse of the ED. Furthermore, these patients will be discharged immediately and therefore future cardiovascular risk should be minimal to reduce forthcoming events. This translates into a need for the highest safety margin possible for any rule-out algorithm. On the other hand, the early identification and treatment of AMI-patients is also important, as early treatment improves outcomes for acute coronary syndrome patients [2]. Whether this treatment might be medical or interventional therapy has to be clarified by the clinical setting, but it would be optimal if future diagnostic strategies could differentiate between patients in need of percutaneous coronary interventions and those who are best managed medically. Therefore, there is an unmet need for differentiating between AMI patients caused by either plague rupture that needs percutaneous coronary interventions or other noncoronary forms of myocardial damage.

\section{Current diagnostic algorithms}

Cardiac troponin is released during myocardial injury and is well established in acute cardiac care. Current European Society of Cardiology (ESC) guidelines recommend a troponin-based algorithm with serial measurement after $3 \mathrm{~h}$ to rule-out or rule-in AMI [3]. The diagnostic cut-off concentration is recommended at the assay-specific 99th percentile. This approach has been shown to be safe and cost-effective in the ED [4-6]. The use of more sensitive troponin assays enables the detection of lower troponin-concentrations, which can be measured in up to $96 \%$ of the general population $[7,8]$. Using highsensitivity troponin-assays, a much lower cut-off concentration has been suggested to enable a rapid rule-out or rule-in after only 1 or $2 \mathrm{~h}[9,10]$. In the ADAPT trial a serial measurement of high-sensitivity troponin I (hs-TnI) after $2 \mathrm{~h}$ showed a low rate of major adverse cardiac events after 30 days, when combined with a normal ECG and a negative TIMI-score [10]. The APACE cohort showed in 1811 patients, that a hs-TnI based algorithm after $1 \mathrm{~h}$ had a high negative predictive value (NPV) of $99.6 \%$ [9]. Importantly the suggested cut-off concentration was only $5 \mathrm{ng} / \mathrm{L}$ combined with an absolute change of $2 \mathrm{ng} / \mathrm{L}$ after $1 \mathrm{~h}$. The rule-in of AMI was suggested for individuals with an absolute hs-TnI increase of $6 \mathrm{ng} / \mathrm{L}$. This resulted in a positive predictive value of $74 \%$ and included most of the AMI patients. In the recently presented BACC cohort, the NPV was $99.8 \%$ for a cut-off concentration of $6 \mathrm{ng} / \mathrm{L}$ after $1 \mathrm{~h}$ for the final diagnosis of NSTEMI type 1. This approach was noninferior compared with

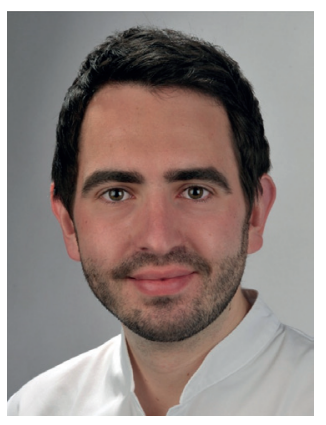

Johannes Tobias Neumann General \& Interventional Cardiology, University Heart Center Hamburg, Hamburg, Germany

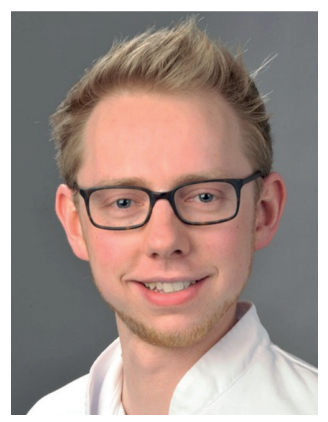

Nils Arne Sörensen

General \& Interventional Cardiology, University Heart Center Hamburg, Hamburg, Germany

Dirk Westermann Author for correspondence: General \& Interventional Cardiology, University Heart Center Hamburg, Hamburg, Germany d.westermann@uke.de 
a 3-h approach [11]. These concentrations are much lower, as compared of the assay-specific 99th percentile at $27 \mathrm{ng} / \mathrm{L}$.

An alternative rule-out approach has been investigated using only a single troponin measurement. A negative high-sensitivity troponin $\mathrm{T}$ (hs-TnT below $5 \mathrm{ng} / \mathrm{L}$ ) in combination with a normal ECG showed a high NPV of $99.8 \%$ for AMI in a large population of 14,636 individuals in the ED [12]. A recently published study by Shah et al. investigated the more sensitive hs-TnI in 6304 patients with suspected AMI [13]. The immediate discharge of patients with a hs-TnI below $5 \mathrm{ng} / \mathrm{L}$ resulted in a $99.6 \% \mathrm{NPV}$. Importantly the NPV was much lower for early-presenters that had symptom onset only $2 \mathrm{~h}$ prior to presentation. The 2015 ESC guidelines already represent the approach of a single hsTnI measurement or a rapid algorithm after only $1 \mathrm{~h} \mathrm{[3].}$ In summary, individuals with a very low troponin concentration, using a high-sensitivity assay, have a low risk of cardiovascular events. This is also represented in the general population, where a low hs-TnI was associated with a low rate of long-term cardiovascular events [8].

Besides high-sensitivity troponin, various other biomarkers have been investigated to triage AMIpatients. The heart-type fatty acid binding protein (htFABP) and copeptin have been the most promising. $\mathrm{HtFABP}$ is a cytoplasmatic protein from the myocardial cell that shows an early increase after myocardial injury, but failed to increase the accuracy of AMIdiagnosis when added to high-sensitivity troponin [14]. Copeptin is a stabile fragment of vasopressin, which is released in acute stress and showed an increase rapidly after AMI [15]. When combined with highsensitivity troponin, the accuracy of rule-out might

\section{References}

1 Nawar EW, Niska RW, Xu J. National Hospital Ambulatory Medical Care Survey: 2005 emergency department summary. Adv. Data (386), 1-32 (2007).

2 Mehta SR, Granger CB, Boden WE et al. Early versus delayed invasive intervention in acute coronary syndromes. N. Engl. J. Med. 360 (21), 2165-2175 (2009).

3 Roffi M, Patrono C, Collet J-P et al. 2015 ESC guidelines for the management of acute coronary syndromes in patients presenting without persistent ST-segment elevation: task force for the management of acute coronary syndromes in patients presenting without persistent ST-segment elevation of the European Society of Cardiology (ESC). Eur. Heart J. 37(3) 267-315 (2015).

4 Keller T, Zeller T, Peetz D et al. Sensitive troponin I assay in early diagnosis of acute myocardial infarction. N. Engl. J. Med. 361, 868-877 (2009).

5 Keller T, Zeller T, Ojeda F et al. Serial changes in highly sensitive troponin I assay and early diagnosis of myocardial infarction. JAMA 306, 2684-2693 (2011). be slightly improved in low-risk individuals and the duration of stay in the ED shortened. Nevertheless these biomarkers did not yet substantially improve the diagnostic algorithms in the ED.

\section{Conclusion \& future perspective}

The major progress in the triage of patients with suspected AMI has been the application of more sensitive troponin assays. The use of much lower cut-off concentrations allows rapid risk stratification at baseline or after $1 \mathrm{~h}$. This concept translates into rapid rule-out of most ED patients ( $\sim 50 \%)$ and rule-in of AMI patients $(\sim 15 \%)$ that can receive immediate treatment [11]. Importantly, patients with elevated, but stable troponin concentrations have an increased cardiovascular risk and should be handled carefully. These individuals should be further observed, receive serial troponin testing and might need further investigation for other causes of symptoms or stress testing to rule-out unstable angina. Importantly, this field is still plagued by limited data and controlled approaches are clearly needed to overcome bias of cohort or register studies. Therefore, randomized clinical trials are paramount and now on their way to be initiated.

\section{Financial \& competing interests disclosure}

The authors have no relevant affiliations or financial involvement with any organization or entity with a financial interest in or financial conflict with the subject matter or materials discussed in the manuscript. This includes employment, consultancies, honoraria, stock ownership or options, expert testimony, grants or patents received or pending, or royalties.

No writing assistance was utilized in the production of this manuscript.

6 Vaidya A, Severens JL, Bongaerts BWC et al. High-sensitive Troponin $\mathrm{T}$ assay for the diagnosis of acute myocardial infarction: an economic evaluation. BMC Cardiovasc. Disord. 14, 77 (2014).

7 Apple FS, Ler R, Murakami MM. Determination of 19 cardiac troponin I and $\mathrm{T}$ assay 99th percentile values from a common presumably healthy population. Clin. Chem. 58(11), 1574-1581 (2012).

8 Zeller T, Tunstall-Pedoe H, Saarela $\mathrm{O}$ et al. High population prevalence of cardiac troponin I measured by a high-sensitivity assay and cardiovascular risk estimation: the MORGAM Biomarker Project Scottish Cohort. Eur. Heart J. 35, 271-281 (2014).

9 Rubini Gimenez M, Twerenbold R, Jaeger C et al. One-hour rule-in and rule-out of acute myocardial infarction using high-sensitivity cardiac troponin I. Am. J. Med. 128, 861. e864-870.e864 (2015).

10 Than M, Cullen L, Aldous S et al. 2-hour accelerated diagnostic protocol to assess patients with chest pain symptoms using contemporary troponins as the only 
biomarker: the ADAPT trial. J. Am. Coll. Cardiol. 59, 2091-2098 (2012).

11 Neumann J, Sörensen N, Schwemer T et al. Accurate and rapid diagnosis of myocardial infarction using a highsensitivity troponin I 1-hour algorithm. Presented at: European Society of Cardiology 2015 Congress, London, UK, 29 August-2 September 2015.

12 Bandstein N, Ljung R, Johansson M, Holzmann MJ. Undetectable high sensitivity cardiac troponin T level in the emergency department and risk of myocardial infarction. J. Am. Coll. Cardiol. 63, 2569-2578 (2014).
13 Shah AS, Anand A, Sandoval Y et al. High-sensitivity cardiac troponin I at presentation in patients with suspected acute coronary syndrome: a cohort study. Lancet 386(10012), 2481-2488 (2015).

14 Reiter M, Twerenbold R, Reichlin T et al. Heart-type fatty acid-binding protein in the early diagnosis of acute myocardial infarction. Heart 99(10), 708-714 (2013).

15 Mockel M, Searle J, Hamm C et al. Early discharge using single cardiac troponin and copeptin testing in patients with suspected acute coronary syndrome (ACS): a randomized, controlled clinical process study. Eur. Heart J. 36(6), 369-376 (2015). 